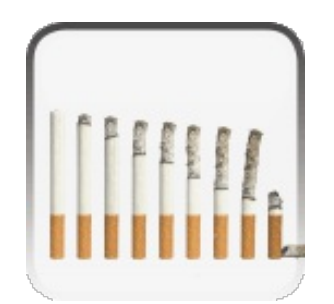

\title{
Life-Course Smoking Behavior
}

Dean Lillard and Rebekka Christopoulou

Publisher: Oxford University Press

Print ISBN-13: 9780199389100

DOI: $10.1093 / \mathrm{med} / 9780199389100.001 .0001$
Print Publication Date: May 2015

Published online: Aug 2015

\section{Smoking by Women in Cross-Country Perspective a}

Chapter: Smoking by Women in Cross-Country Perspective

Author(s): Rebekka Christopoulou and Zeynep Önder

DOI: $10.1093 / \mathrm{med} / 9780199389100.003 .0012$

\section{Introduction}

Although smoking is generally more widespread in male populations, women also smoke in large numbers. According to the World Health Organization (WHO), nearly 250 million women in the world are daily smokers. In developed countries, smokers comprise approximately 22 percent of the female population, whereas the corresponding share in developing countries is 9 percent. ${ }^{1}$ Although in several developed countries smoking among women is currently declining (e.g., Australia, Canada, the United Kingdom, and the United States), in many other countries the habit is still spreading.

Governments should be generally concerned when a high proportion of the population smokes, but they have additional reason to be concerned when women's smoking rates are high because, unlike men, women who smoke directly affect not only their own health but also the health of their current and future children. Apart from the well-known effect of smoking on cancer and cardiac disease, clinical research has shown that smoking among women is associated with adverse endocrine changes (including increases in menstrual problems), reproductive difficulties, complications of 
pregnancy, low fetal birthweight, higher fetus toxicity, decreased quantity and quality of breastfeeding, and sudden infant death syndrome (Nusbaum et al., 2000). Researchers have also shown that prenatal and postnatal exposure to tobacco smoke may affect children's long-term development; for example, it has been associated with attention deficit disorder and other behavioral problems during childhood (Milberger et al., 1996, 1998; McCrory and Layte, 2012). In fact, many of the previously mentioned associations are demonstratively causal (see the review of evidence in US Department of Health and Human Services, 2014).

To develop policies that ameliorate the se many adverse effects, one must first understand what causes women to start and to continue to smoke. However, this task is not straightforward. Studies have shown that the smoking behavior of women differs from that of men in ways that cannot be explained by observable characteristics such as income, age, education, and marital status (Bauer et al., 2007). In other words, there are gender-specific factors that cause women to make different smoking decisions compared to observationally identical men. For example, researchers have found that, all else equal, women are less likely to smoke than men, but once they start smoking, they are less likely to quit and more likely to relapse after an attempt to quit. However, not all evidence supports these patterns (Hersch, 1996; Ward et al., 1997; Osler et al., 1999; Jarvis et al., 2013).

Arguably, several biological, socioeconomic, and cultural determinants of smoking behavior are specific to women. The country-specific chapters of this book discussed many of these determinants. Women have special metabolic responses to nicotine; they often command fewer economic resources that they could use to buy cigarettes; they may face social disapproval if they smoke, especially in traditional societies; or they may simply have different preferences than men, such as a low sensitivity to prices and greater concerns for weight gain, depression, and their family members (Glassman et al., 1990; Waldron, 1991; Williamson et al., 1991; McGee and Williams, 2006). At the same time, women's preferences are influenced by targeted advertisements from the tobacco industry and other social forces, such as feminism (Kaufman and Nichter, 2010).

To evaluate the relative importance of these factors, it is necessary to obtain a clear picture of women's smoking patterns over time and across countries. Although previous studies have documented some of this variation (Waldron et al., 1988; Fiore et al., 1989; Pierce, 1989; Husten et al., 1996; Thun et al., 2012), they examined a narrow time period, a small set of countries, or indicators of smoking behavior that do not fully reflect population exposure to smoking-related health risks (e.g., they examined smoking rates but not cigarette consumption). Throughout this book, we widened the scope of the analysis on all these dimensions. In this chapter, we compare indicators of smoking prevalence, cigarette consumption, age of initiation, and age of cessation across the seven generations of women in the 10 countries of study. We then consider the existing evidence and propose possible hypotheses to explain the observed smoking patterns.

\section{Cross-Country Patterns in Smoking Behavior}

Figure 12.1 plots the peak smoking prevalence rates of each birth cohort (defined by age in 2002) in each country. ${ }^{2}$ At first glance, this figure shows no clear patterns because there are significant differences across countries in both the intergenerational evolution and the level of peak prevalence. Of all cohort country groups, at their peak smoking prevalence rate, 40- to 49-year-old Canadian women smoked the most (at 55 percent) and 20- to 29-year-old Chinese women smoked the least (at nearly 0 percent). 


\section{Smoking by Women in Cross-Country Perspective}

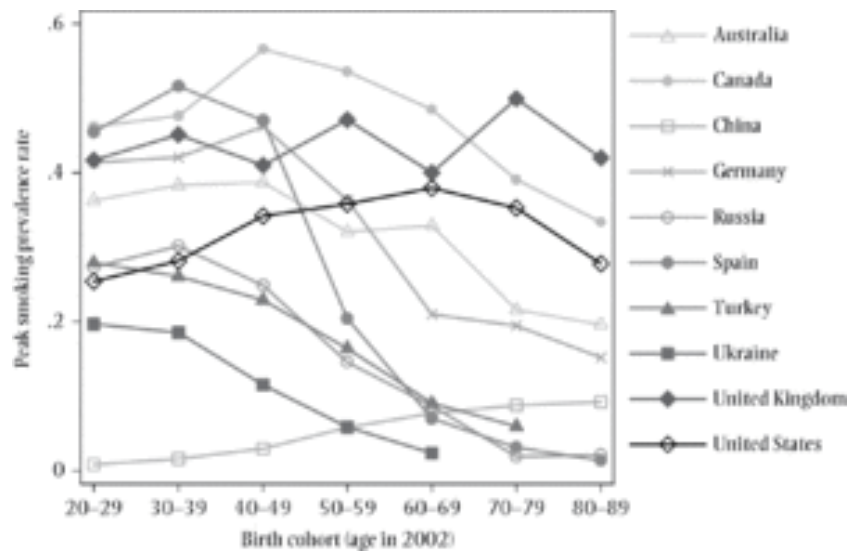

Click to view larger

Download figure as PowerPoint slide

Figure 12.1

Peak smoking prevalence rate by country and cohort.

Despite the apparent idiosyncratic smoking patterns, there are systematic similarities in Figure $\mathbf{1 2 . 1}$ that are easier to recognize from the perspective of the "cigarette epidemic" model developed by Lopez et al. (1994) and Thun et al. (2012). These authors argue that, as countries develop economically, the prevalence of smoking among women grows to a peak and then declines (lagging that of men by a few decades). In Figure 12.1, one observes such a hump-shaped pattern across cohorts, although the pattern is more evident for some countries than for others. In Australia, Canada, Germany, Russia, Spain, and the United States, the peak smoking prevalence rate first increases and then decreases across successively younger cohorts. In Turkey and Ukraine, peak smoking prevalence monotonically increases across successive generations, but the increase has already started to slow down among the very young cohorts. In the former group of countries, Spain and Russia reach their peak in the cohort of 30- to 39-year-olds; Canada, Germany, and Australia do so in the cohort of 40- to 49-year-olds; and the United States does so in the cohort of 60- to 69-year-olds. In the latter group, the peak is of course highest for the cohort that is 20-29 years old. Consistent with the cigarette epidemic model, these differences suggest that economically mature countries are at more advanced stages of smoking diffusion relative to newly developed or developing countries.

Across successive cohorts in China and the United Kingdom, however, the cross-cohort pattern of peak smoking prevalence rates does not match the cigarette epidemic story very well. In China, peak smoking prevalence declines across successive generations; that is, it shows symptoms of an advanced stage of smoking diffusion even though China is among the most recently developed countries we study (it started developing quickly after the late 1970s). In the United Kingdom, peak smoking prevalence follows a zigzag course across successive cohorts, and it shows no long-term trend whatsoever. As we discussed in the respective country-specific chapters, it is likely that the female smoking behavior in China and the United Kingdom has been influenced more by cultural and social factors and less so by economic factors. Specifically, in China, smoking became increasingly incompatible with the socially accepted role of women in society, whereas in the United Kingdom, the ups and downs of peak smoking prevalence seem to correspond to the three waves of feminism that emerged during the study period.

Although the peak prevalence rate approximates how popular the smoking habit is, it says nothing about how heavily people smoke. In Figure 12.2, we plot, for each cohort in each country, the 
number of cigarettes that current and former smokers consumed on the average day when they smoked. ${ }^{3}$ Interestingly, like smoking prevalence, cigarette consumption also appears to be associated with a country's economic development. Consumption is higher in the advanced economies (highest in almost all US cohorts) and lower in the emerging economies (lowest in almost all Ukrainian cohorts). Moreover, it forms a hump-shaped pattern across successive generations, which seems to be consistently timed across countries; that is, it is generally higher among the middle-aged cohorts and lower among younger and older cohorts. Again, there are exceptions. For example, as discussed in the chapter on China, while smoking prevalence is monotonically falling across successively younger cohorts, average cigarette consumption is monotonically increasing. Thus, although fewer women smoke in China in successively younger cohorts, the ones who do smoke are increasingly heavy smokers.

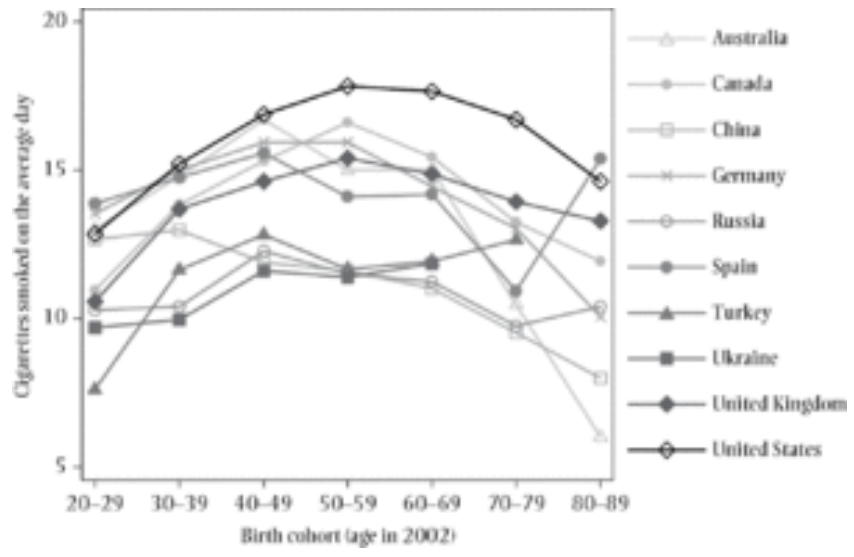

- Click to view larger

Download figure as PowerPoint slide

Figure 12.2

Number of cigarettes smoked on average day by country and cohort.

Of course, the popularity and intensity indicators alone do not fully reflect population exposure to smoking health risks because they miss information on the persistence of the smoking habit. One can deduce such information from the dynamics in smoking initiation and cessation. To this purpose, we respectively plot in Figures $\mathbf{1 2 . 3}$ and $\mathbf{1 2 . 4}$ the average age at which female smokers start and quit smoking by birth cohort and country. Recall that, by construction, quit age increases with cohort age and, therefore, cannot be compared across cohorts. For this reason, in Figure 12.4, we plot the average quit age in every country relative to average quit age in the United Kingdom. The same limitation potentially holds for the age at smoking initiation (i.e., it may increase with cohort age by construction) but to a much lesser extent. ${ }^{4}$ Thus, we report data on initiation age in absolute terms.

Click to view larger

Download figure as PowerPoint slide 


\section{Smoking by Women in Cross-Country Perspective}

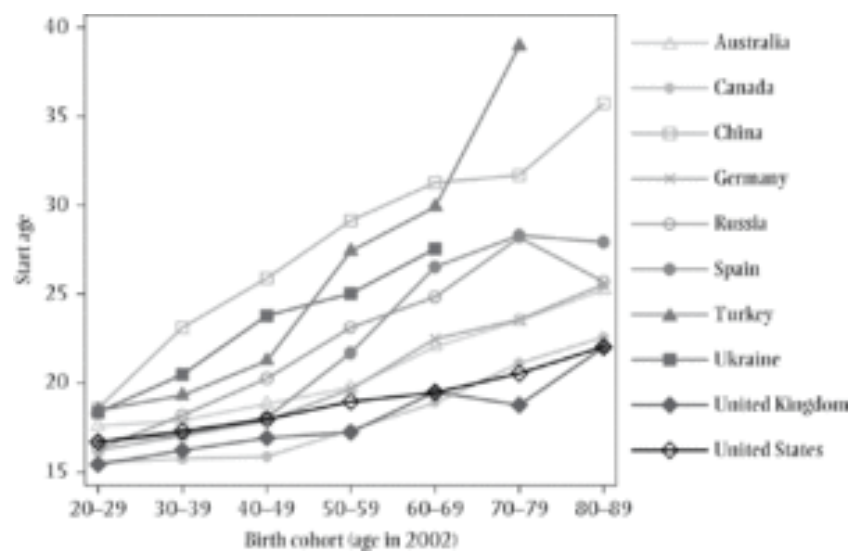

Figure 12.3

Average age of smoking initiation by country and cohort.

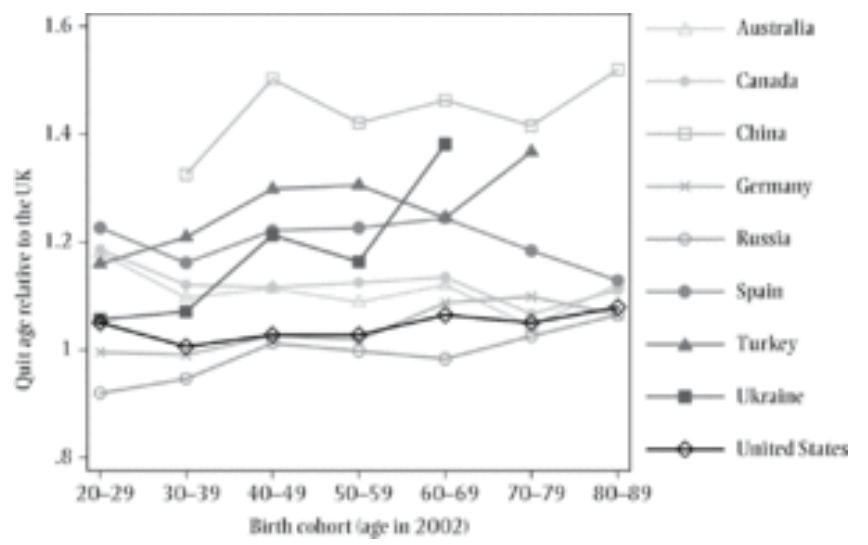

Click to view larger

Download figure as PowerPoint slide

Figure 12.4

Average age of smoking cessation by country and cohort (relative to the United Kingdom).

Figure 12.3 shows that the average start age among female smokers is lower in mature economies (lowest in the United States, United Kingdom, and Canada) and higher in emerging economies (highest in China, Turkey, and Ukraine). In all but a few cases, female smokers in any given generation started to smoke at a younger age than did smokers in the generation that immediately preceded them. Strikingly, the average age of initiation has not only declined across successive cohorts but also converged to a common value. Because older women in developing economies started smoking at much older ages than did those in mature economies, their average age of smoking initiation has fallen more and faster. For example, the average start age was slightly less than 40 years in the cohort of Turkish women age 70-79 years in 2002 and approximately 35 years in the cohort of Chinese women age 80-89 years in 2002. In both countries, it declined below 20 years in the 20- to 29-year-old cohorts (although the decline was much faster in Turkey). By contrast, the average start age in the United Kingdom declined by only 5 years, from 21 (80- to 89year-old cohort) to 16 years (20- to 29-year-old cohort).

Finally, Figure 12.4 shows that, unlike the three previous indicators of smoking behavior, the average quit age does not follow a consistent pattern across more and less developed countries. 
The absence of a consistent pattern arises mostly because quit behavior of female smokers in Russia differs from quit behavior in other developing economies. Specifically, women who smoke in China and Turkey wait the longest to quit relative to both women smokers in the United Kingdom and smokers in other countries. Although one would expect a similar pattern among Russian women, our data show that they quit much earlier. In fact, apart from Russia, in no other country do female smokers quit before female smokers in the United Kingdom.

Taken together, the patterns in Figures $\mathbf{1 2 . 3}$ and 12.4 lead us to conclude that in the economically mature countries (especially in the English-speaking countries we study), female smokers start smoking when they are relatively young but also quit smoking when they are young. By contrast, in less developed countries, female smokers start smoking at older ages but also quit much later. Russia is an interesting exception to this pattern because Russian female smokers start smoking at older ages and quit smoking when they are relatively young.

\section{Predictors of Smoking Behavior of Women}

The systematic patterns across age cohorts that we just documented clearly suggest that economic development could play an important role in the determination of female smoking patterns. Apart from the authors of the cigarette epidemic model, other researchers have also suggested such a role (e.g., Schaap et al., 2009). They all acknowledge that economic development may have diverse effects on smoking outcomes both over time and across demographic groups. As economies develop, individuals and firms access more resources and, therefore, the demand for and supply of cigarettes increases. However, a host of other political, social, cultural, and technological changes take place concurrently, each of which may reinforce or counteract the income effect on smoking.

First, economic development in modern history is linked with industrialization, which in turn is linked with urbanization and waged work. In urbanized societies, more women formally participate in the labor force and thereby get command over economic resources. Also, more women live in small households (as opposed to large rural households that encompass the extended family) and enjoy urban anonymity; thus, they face less familial and social pressure against their smoking. In addition, economies typically prosper in democratic regimes, where laws establish women's rights and information flows freely. In these regimes, women tend to have easier access to cigarettes and face less social disapproval when they smoke, but they are also more exposed to information about the health risks of smoking (given that such information exists). Economic development also weakens dependencies between governments and specific industries, including the tobacco industry. Thus, governments can afford to oppose the industry's interests by increasing cigarette taxes. At the same time, they can afford to spend more on education (expanding their system to include more women) and on tobacco control policies (increasing awareness about the health effects of smoking in general and on women in particular).

To provide some simple evidence about how such factors relate to the female smoking rates in our set of countries, in Table 12.1 we report a set of correlation coefficients. Specifically, we regress the female smoking prevalence rate of each cohort in each year in all 10 countries against countryspecific time-series indicators, each of which represents some aspect of the national context in which women were taking their smoking decisions. The set includes gross domestic product (GDP) per capita as a measure of development and a number of variables that co-vary with developmentnamely, an index of democracy, cigarette prices, female labor force participation, two measures of 
urbanization (population density and the share of rural population), female educational attainment, and total births per woman. ${ }^{5}$ Because these variables significantly co-vary, we run separate regressions for each one while also controlling for age, age-squared, as well as country, year, and cohort fixed effects.

Table 12.1. Correlation of Smoking Prevalence of Women with Selected Variables (Estimates from Linear Regressions)

\begin{tabular}{|l|l|l|l|l|}
\hline Variable & Coefficient & Standard error & Observations & $\boldsymbol{R}^{2}$ \\
\hline GDP per capita & $0.0035^{* * *}$ & $(0.0006)$ & 3986 & 0.6879 \\
\hline Democracy & $0.0030^{* * *}$ & $(0.0004)$ & 3794 & 0.6875 \\
\hline Cigarette price & $-0.0044^{*}$ & $(0.0024)$ & 3045 & 0.6842 \\
\hline Labor force participation rate & $0.0015^{* *}$ & $(0.0008)$ & 1804 & 0.6984 \\
\hline Population density & 0.0003 & $(0.0002)$ & 3071 & 0.6869 \\
\hline Share of rural population & $-0.0020^{* * *}$ & $(0.0004)$ & 3135 & 0.6877 \\
\hline Educational attainment & $0.0175^{* * *}$ & $(0.0029)$ & 3384 & 0.6948 \\
\hline Fertility rate & $-0.0150^{* * *}$ & $(0.0030)$ & 3119 & 0.6883 \\
\hline
\end{tabular}

NOTES: Each row reports statistics from a separate ordinary least squares regression. Data are at the country, birth cohort, and year level of observation. All regressions control for mean cohort age and age-squared, country dummies, year dummies, and birth cohort dummies. GDP per capita is in 1990 International Geary-Khamis dollars '0,000s (source: Maddison, 2010).

Democracy is a scaled measure of regime governance that takes values from -10 to 10 (source: Polity IV Project). Cigarette price is in 2008 US dollars, purchasing power parity adjusted (from various national sources; see country-specific chapters). The labor force participation rate is for females of all ages (source: International Labor Office for Ukraine and China; Organization for Economic Cooperation and Development statistics for all other countries). Population density measures people per square kilometer of land area (source: World Development Indicators). Educational attainment measures average years of total schooling for females (source: Barro and Lee, 2010; missing values interpolated). Fertility rate measures total births per woman (source: World Development Indicators).

${ }^{*}, * *$, and ${ }^{* * *}$ indicate statistical significance at the 10,5 , and 1 percent level, respectively.

We find that a greater proportion of women smoke in years when GDP per capita, democracy levels, women's participation in the labor force, and average years of schooling are higher, and fewer women smoke in years when cigarette prices, the share of rural population, and fertility rates are higher. These results find support in previously published evidence. For example, Steckley et 
al. (2003) and Schaap et al. (2009) find a positive (unconditional) correlation of GDP with smoking rates among women, especially among women who are more educated. ${ }^{6}$ Previous studies also report a positive correlation between female smoking and educational attainment in less developed countries (e.g., in southern Europe; Cavelaars et al., 2000) where cigarette diffusion is still at early stages, whereas in more developed countries, higher education is generally associated with a lower risk of smoking among women. It is possible that the less developed countries in our sample drive the negative correlation we find in our results. Finally, previous studies also report a positive correlation between female smoking and urbanization. For example, Pomerleau et al. (2004) found that living in larger urban areas was the strongest predictor of smoking among women in countries of the former Soviet Union. They interpret their finding to reflect that urban women have higher exposure to Western influences and to aggressive advertising campaigns by Western tobacco companies. Similar evidence is also reported in Missouri Department of Health (1995), Pudule et al. (1999), and Idris et al. (2007).

Interestingly, the correlation between smoking and fertility may arise via different channels. Lower fertility may be correlated with higher smoking because they are both consequences of changes in social norms about gender roles. That is, as women become emancipated, they are both more likely to smoke and more likely to use birth control. However, the negative correlation may also arise because smoking affects women's ability to conceive, carry, and deliver healthy children. Both effects work in the same direction.

Finally, the negative correlation between smoking rates and cigarette prices is according to theory. This correlation corresponds to a price elasticity of smoking of -0.07-an estimate that falls at the very low end of the range of elasticities reported in other studies (although most studies report price elasticity of cigarette consumption rather than that of smoking prevalence or participation). For US women, Chaloupka (1990) finds a positive price elasticity of cigarette demand that ranges from 0.852 to 1.41 , but all other US estimates are negative and range from -0.118 to -0.510 (Lewit and Coate, 1982; Hersch, 2000; Stehr, 2007). Studies from other countries also find comparable results. Mao et al. (2003) report a price elasticity of cigarette consumption in China of -0.69 , Lee et al. (2004) report a price elasticity of smoking intensity in Taiwan of -0.14 , and Oglobin and Brock (2003) report a price elasticity of smoking prevalence among Russian women of -0.628.

Two potential predictors of female smoking are missing from Table 12.1 because we lack the necessary data: (1) anti-smoking publications and campaigns and (2) cigarette advertising. Both transmit information that likely affects how women assess the cost and utility of smoking. For example, cigare tte advertisements that target women may convince women that they will benefit if they smoke because the advertising emphasizes that being slim is important and that smoking helps with weight control. Similarly, anti-smoking publications and campaigns inform women that smoking negatively affects not only their own health but also their childbearing prospects and their children's health. Although there are no available time-series indicators we can use to capture these informational forces, ${ }^{7}$ in the country-specific chapters, we reported key dates when these forces likely started (e.g., with publications of research articles on the smoking health effects and/or official government publications) or ended (e.g., through regulatory advertisement bans in certain media). In all the countries we study, pro-smoking information generally precedes anti-smoking information, but after a period of overlap timed immediately after the 1950s-when scientists began to demonstrate the health effects of smoking-the latter eventually dominates. We conjecture that these informational shifts may be the leading predictors of the hump-shaped pattern in cigarette consumption that is common across most countries in our sample. 


\section{Conclusion}

In summary, we find that the variation of smoking prevalence across countries and cohorts is generally consistent with the predictions of the cigarette epidemic model. Our descriptive analysis shows that smoking diffusion among women in advanced economies is wider but unfolds earlier relative to emerging economies. Our correlation analysis shows that more women smoke as countries become richer and more democratic; as more women participate in education and in formal work; and when cigarette prices, urbanization, and fertility rates are low.

However, unlike the cigarette epidemic model, we do not rely solely on smoking prevalence data. We also show that female smokers in advanced countries consume more cigarettes, initiate smoking, and also quit smoking at younger ages than women in developing countries. Finally, we show that in virtually all countries, the average age at smoking initiation decreases across successive generations, and cigarette consumption is higher among cohorts who came of age after World War II (when most countries started developing) and before the 1970s (when information about the health consequences of smoking started to spread).

In some countries, women's smoking patterns deviate from these patterns. For example, although China and Russia are among the least developed countries in our sample, in China, female smoking prevalence declines monotonically across successive generations, whereas in Russia, women start smoking at relatively old ages but quit smoking while relatively young. In addition, although the United Kingdom is among the most economically advanced countries in our sample, smoking rates of British women show no long-term trend. We interpret these deviations to suggest an important role for social norms and cultural influences, which may be strong enough to dominate over other determinants of smoking behavior.

\section{References}

Barro, R. and J.-W. Lee, April 2010, "A new data set of educational attainment in the world, 19502010.” Journal of Development Economics 104:184-198.

Bauer, T., S. Göhlmann, and M. Sinning. 2007. “Gender differences in smoking behavior.” Health Economics 16:895-909.

Cavelaars, A. E., A. E. Kunst, J. J. Geurts, R. Crialesi, L. Grötvedt, U. Helmert, et al. 2000.

"Educational differences in smoking: International comparison." British Medical Journal 320:11021107.

Chaloupka, F. J. 1990. "Men, women and addiction: The case of cigarette smoking." NBER Working Paper No. 3267. Cambridge, MA: National Bureau of Economic Research.

Christopoulou, R., D. R. Lillard, and J. B. Miyar. 2013. "Smoking behavior of Mexicans: Patterns by birth-cohort, gender, and education." International Journal of Public Health 58:335-343.

Fiore, M. C., T. E. Novotny, J. P. Pierce, E. J. Hatziandreu, K. M. Patel, and R. M. Davis. 1989. "Trends in cigarette smoking in the United States: The changing influence of gender and race." Journal of the American Medical Association 261:49-55.

Glassman, A. H., J. E. Helzer, L. S. Covey, L. B. Cottler, F. Stetner, J.E. Tipp, et al. 1990. “Smoking, 
smoking cessation, and major depression." Journal of the American Medical Association 264:15461549 .

Hersch, J. 1996. "Smoking, seat belts, and other risky consumer behaviors: Differences by gender and race." Managerial and Decision Economics 17:471-481.

Hersch, J. 2000. "Gender, income levels, and the demand for cigarettes." Journal of Risk and Uncertainty 21:263-282.

Husten, C. G., J. H. Chrismon, and M. N. Reddy. 1996. "Trends and effects of cigarette smoking among girls and women in the United States, 1965-1993." Journal of the American Medical Women's Association 51:11-18.

Idris, B. I., K. Giskes, C. Borrell, J. Benach, G. Costa, B. Federico, et al. 2007. "Higher smoking prevalence in urban compared to non-urban areas: Time trends in six European countries." Health \& Place 13:702-712.

Jarvis, M. J., J. E. Cohen, C. D. Delnevo, and G. A. Giovino. 2013. "Dispelling myths about gender differences in smoking cessation: Population data from the USA, Canada, and Britain." Tobacco Control 22:356-360.

Kaufman, N., and M. Nichter. 2010. "The marketing of tobacco to women: Global perspectives." In Women and the Tobacco Epidemic: Challenges for the 21st Century, edited by J. M. Samet and S. Y. Soon, pp 69-99. Geneva: World Health Organization.

Lee, J. M., T. S. Hwang, C. Y. Ye, and S. H. Chen. 2004. "The effect of cigarette price increase on cigarette consumption in Taiwan: Evidence from the National Health Interview Surveys on cigarette consumption." BMC Public Health 4:61.

Lewit, E. M., and D. Coate. 1982. "The potential for using excise taxes to reduce smoking." Journal of Health Economics 1:121-145.

Lillard, D. R. 2014. "Health information and smoking: New (improved) estimates of how information affects behavior." Paper presented at the 5th Biennial Conference of the American Society of Health Economists, University of Southern California, Los Angeles, June 22-25.

Lopez, A. D., N. E. Collishaw, and T. Piha. 1994. "A descriptive model of the cigarette epidemic in developed countries." Tobacco Control 3:242-247.

Mao, Z. Z., Y. G. Huan, M. J. Min, J. Samet, and M. Ceraso. 2003. "Adults demand of cigarettes and its influencing factors in China." Soft Science of Health 17:19-23.

McCrory, C., and R. Layte. 2012. "Prenatal exposure to maternal smoking and childhood behavioural problems: A quasi-experimental approach." Journal of Abnormal Child Psychology 40:1277-1288.

McGee R., and S. Williams. 2006. "Predictors of persistent smoking and quitting among women smokers." Addictive Behaviors, 31:1711-1715.

Milberger S., J. Biederman, S. V. Faraone, L. Chen, and J. Jones. 1996. "Is maternal smoking during pregnancy a risk factor for attention deficit hyperactivity disorder in children?" American Journal of Psychiatry 153:1138-1142. 
Milberger S., J. Biederman, S. V. Faraone, and J. Jones. 1998. "Further evidence of an association between maternal smoking during pregnancy and attention deficit hyperactivity disorder: Findings from a high-risk sample of siblings." Journal of Clinical Child Psychology 27:352-358.

Missouri Department of Health. 1995. "Prevalence of smoking by area of residence-Missouri, 1989-1991.” Morbidity and Mortality Weekly Report 44:494-497.

Nusbaum M. L., M. Gordon, D. Nusbaum, M. A. McCarthy, and D. Vasilakis. 2000. "Smoke alarm: A review of the clinical impact of smoking on women." Primary Care Update for Ob/Gyns 7:207-214.

Oglobin, C., and G. Brock. 2003. "Smoking in Russia: The 'Malboro Man' rides but without 'Virgina Slims' for now." Comparative Economic Studies 45:87-103.

Osler, M., E. Prescott, N. Godtfredsen, H. O. Hein, and P. Schnohr. 1999. "Gender and determinants of smoking cessation: A longitudinal study." Preventative Medicine 29:57-62.

Pierce, J. P. 1989. "International comparisons of trends in cigarette smoking prevalence." American Journal of Public Health 79:152-157.

Pomerleau, J., Gilmore, A., McKee, M., Rose, R., and C. W. Haerpfer. 2004. "Determinants of smoking in eight countries of the former Soviet Union: Results from the Living Conditions, Lifestyles and Health Study." Addiction 99(12):1577-1585.

Pudule, I., D. Grinberga, K. Kadziauskiene, A. Abaravicius, S. Vaask, A. Robertson, et al. 1999. "Patterns of smoking in the Baltic Republics." Journal of Epidemiology and Community Health 53:277-282.

Schaap, M. M., A. E. Kunst, M. Leinsalu, E. Regidor, A. Espelt, O. Ekholm, et al. 2009. "Female ever-smoking, education, emancipation and economic development in 19 European countries." Social Science \& Medicine 68:1271-1278.

Steckley, S. L., W. B. Pickworth, and H. W. Haverkos. 2003. "Cigarette smoking and cervical cancer. Part II: A geographic variability study.” Biomedicine \& Pharmacotherapy 57:78-83.

Stehr, M. 2007. "The effect of cigarette taxes on smoking among men and women." Health Economics 16:1333-1343.

Thun, M., R. Peto, J. Boreham, and A. D. Lopez. 2012. "Stages of the cigarette epidemic on entering its second century." Tobacco Control 21:96-101.

US Department of Health and Human Services (USDHHS). 2014. The Health Consequences of Smoking-50 Years of Progress. A Report of the Surgeon General. Atlanta, GA: USDHHS, Centers for Disease Control and Prevention, National Center for Chronic Disease Prevention and Health Promotion, Office on Smoking and Health.

Waldron, I. 1991. "Patterns and causes of gender differences in smoking." Social Science and Medicine 32:989-1005.

Waldron, I., G. Bratelli, L. Carricker, W. C. Sung, C. Vogeli, and E. Waldman. 1988. "Gender differences in tobacco use in Africa, Asia, the Pacific, and Latin America." Social Science and Medicine 27:1269-1275. 
Ward, K. D., R. C. Klesges, S. M. Zbikowski, R. E. Bliss, and A. J. Garvey. 1997. "Gender differences in the outcome of an unaided smoking cessation attempt." Addictive Behaviors 22:521-533.

Williamson D. F., J. Madans, R. F. Anda, J. C. Kleinman, G. A. Giovino, and T. Byers. 1991. "Smoking cessation and severity of weight gain in a national cohort." New England Journal of Medicine 324:739-745.

\section{Notes:}

1. See http://www.who.int/tobacco/en/atlas6.pdf.

2. In this figure, as in all subsequent figures, data are missing for some cohorts because we do not plot smoking data for cohorts with fewer than 50 observations or fewer than five smokers. For Ukraine, no data are available for 80 - to 89 -year-olds.

3. As we note in the Appendix, not all surveys ask ex-smokers to report the number of cigarettes they used to smoke per day when they were smoking regularly. Some surveys collect this information only from current smokers. It follows that we may be mis-estimating cigarette consumption for older cohorts in the corresponding countries because older cohorts have a higher proportion of ex-smokers relative to younger cohorts. Assuming that people who manage to quit smoking are on average lighter smokers than those who do not, we likely overestimate average consumption for these cohorts.

4. Average start age cannot exceed 29 years in the youngest cohort, 39 years in the second youngest cohort, 49 years in the third youngest cohort, etc. However, our data show that the mean start age is generally lower than cohort age (with the exception of the youngest cohort). Thus, cross-cohort comparability should not be compromised (at least concerning all but the youngest cohort).

5. Note that because most time series are available for the more recent periods in each country, the estimated correlations are based on variation in smoking rates in those periods.

6. By contrast, relying on temporal variation from Mexico, Christopoulou et al. (2013) find a small negative association between per capita GDP and female smoking rates, and only for women with higher than primary education.

7. In unpublished work, Lillard (2014) develops a new information index for the United States that tracks individual exposure to information that advocates for and against smoking. He finds that when exposed to the same anti-smoking information, women are much less likely to start and much more likely to quit smoking than men. 